\title{
USING INVERSE MODELING TO ESTIMATE PARAMETER VALUES FOR THREE DIMENSIONAL TRANSPORT OF CONTAMINANTS IN LAKE ONTARIO
}

\author{
HURDOWAR-CASTRO H. \\ TSANIS I.K.*
}

\author{
McMaster University \\ Department of Civil Engineering
}

Canada
Received: 21/05/2013

Accepted: 08/10/2013
* to whom all correspondence should be addressed: e-mail: tsanis@mcmaster.ca

\section{ABSTRACT}

The Great Lakes form an important freshwater drinking source for many urban areas surrounding the Lakes but also provide a sink for pollutants and runoff. Consequently introducing new drinking water intakes into any of these water bodies requires investigation into local pollutant sources and their transport in order to determine the most appropriate location and depth of any new intake.

Two methods involving the calibration of a $3 \mathrm{D}$ wind driven transport model, to spill data collected over a 4 week period, are described. The methods include the traditional trial and error approach and the application of a nonlinear inverse model to optimize parameter estimates. Results show that calibration using the inverse modeling approach was an improvement over the traditional trial and error approach by providing a clear quantitative analysis of parameter sensitivity and importance, and ultimately yielding a better fit between observed and simulated data. The calibrated threedimensional model was ultimately applied to assess the impacts of a potential local pollutant source to several proposed new drinking water intakes located along the north shore of Lake Ontario.

KEYWORDS: 3D transport model, drinking water intakes, model calibration, parameter estimation

\section{INTRODUCTION}

The impacts of an accidental tritiated water spill from a Nuclear Generating Station (PNGS) was evaluated as a result of the station's proximity to the proposed new drinking water intake location as shown in Figure 1 (Hurdowar et. al., 2007). Historical records indicated that one of the most serious tritiated water spills occurred in August 1992. In the aftermath of the spill, tritium data measurements were made at several existing drinking water intakes during the period August 2-27 by Ontario Hydro and the Ontario Ministry of the Environment. The measurements at these existing intakes were believed to provide good coverage of the plume movement over the month long period. Consequently this data was used to calibrate a three-dimensional wind driven model in order to gain information on the possible levels of tritium that would have been experienced at the proposed new intake locations during such a spill event or under similar events.

The model used for this study was the IDOR three-dimensional (3-D) pollutant transport model (Tsanis and Hurdowar, 2005). The IDOR3D model is a wind driven circulation model based on an $\mathrm{x}-$ y Cartesian coordinate and multilayered vertical discretization system and uses a finite difference approach to solve the Reynolds's averaged equations. Initial calibration of the three-dimensional model, to the August 1992 spill data, was carried out based on a trial and error approach, modifying key input parameters until the fit between observed and simulated tritium measurements at the existing intakes was the best achievable. The calibration was based on qualitative and some statistical measures of fit to the field data. The trial and error approach however, proved to be difficult as a result of the large number permutations of parameter values possible. Moreover the parameter set determined in this manner is modeler dependent, consequently a more definitive and efficient method was sought. To assist further in the calibration exercise the inverse model UCODE (Poeter and Hill, 1998) was used to calculate parameter sensitivity and to estimate optimal parameter values using a non linear regression analysis of an objective function (Poeter and Hill, 
1999). UCODE has been used extensively for a number of studies (Essaid et al., 2003; Hoffmann et al., 2003). In general, inverse modeling has been actively applied to assist in groundwater modeling, and ocean and atmospheric circulation modeling. For surface waters inverse modeling has included modeling of one-dimensional setup and alongshore currents (Feddersen et al., 2004), twodimensional river water quality and quantity analysis (Wang and Wang, 2005), and two-dimensional hydrodynamic and pollutant transport modeling (Wang et al., 2006). In this paper field measured long term plume movement was used, in conjunction with inverse modeling, to determine a set of optimal parameter values for the purpose of simulating three-dimensional pollutant transport in a lake environment. The field data comprised of pollutant measurements recorded at existing drinking water intakes located within Lake Ontario over a four week period in the aftermath of a tritiated water spill from the Pickering Nuclear Generation Station. UCODE, as applied in this study, was based on differences between simulated and observed tritium levels at each of the existing intakes.

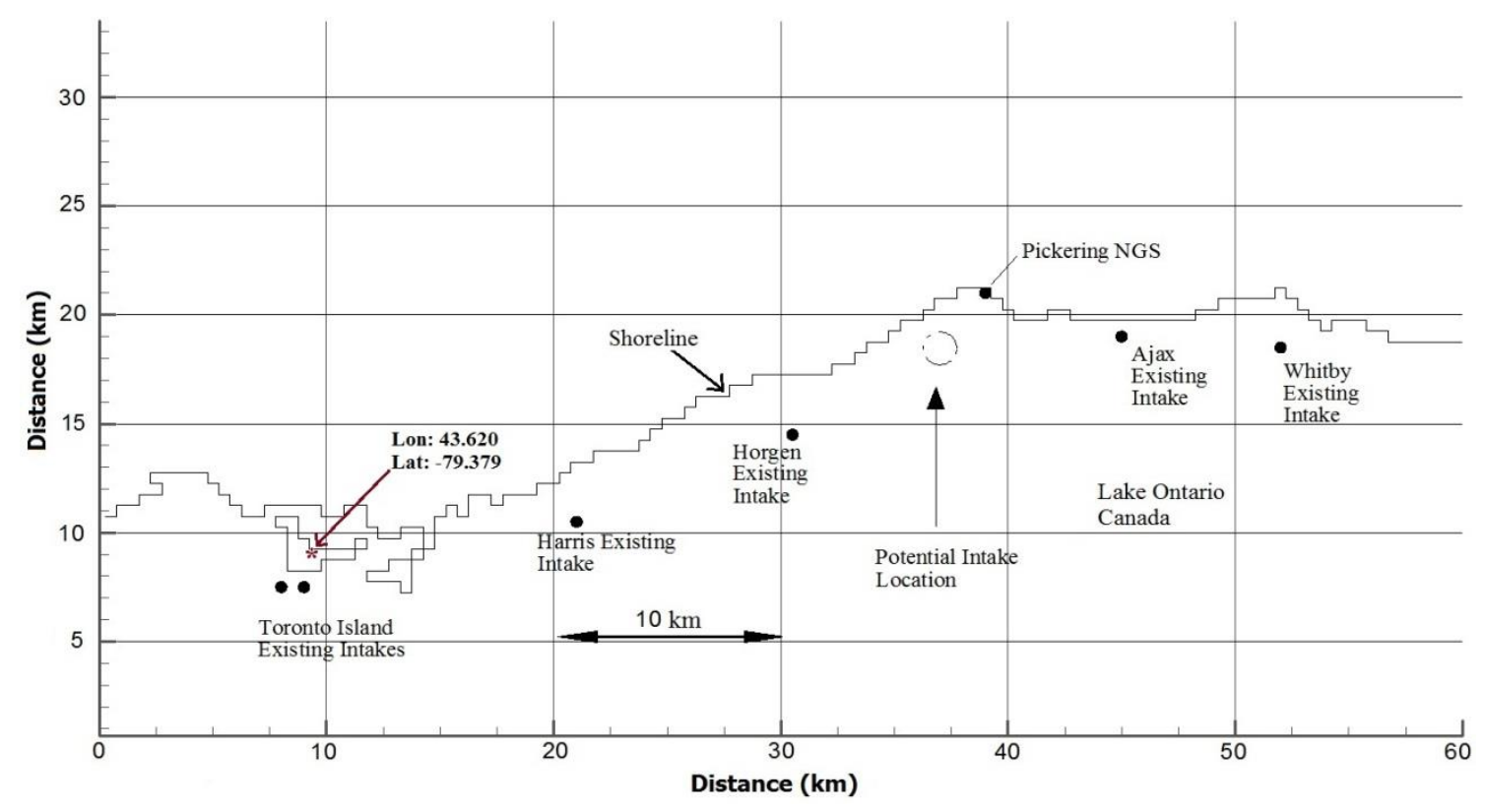

Figure 1. Existing intake locations in north shore of Lake Ontario between Metropolitan Toronto and Whitby. The gridded shoreline is in increments of $500 \mathrm{~m}$

\section{THEORETICAL BACKGROUND The IDOR3D Model}

The IDOR3D model is a 3-D hydrodynamic pollutant transport model that can be run with open or closed boundary conditions. This model has been previously applied successfully for a hydrodynamic study of the near shore area of Lake Ontario (Shen et al. 1995). The threedimensional governing equations for wind-induced circulation used in the model were derived from the Reynolds averaged stress equations under the assumptions of incompressibility, the Boussinesq approximation and the hydrostatic assumption. Under the hydrostatic assumption the vertical accelerations are considered small enough to be ignored simplifying the z-momentum equation to just hydrostatic pressure distribution. More on these assumptions within the IDOR3D model is given in Tsanis and Hurdowar, (2005). Turbulence closure within the IDOR3D model is provided by the eddy viscosity-diffusivity approach (the turbulent transport terms are written in terms of eddy viscosity and diffusivity coefficients $\left(\mathrm{V}_{\mathrm{h}}, \mathrm{v}_{\mathrm{v}}\right),\left(\mathrm{K}_{\mathrm{h}}, \mathrm{K}_{\mathrm{v}}\right)$, and $\left(\mathrm{M}_{\mathrm{h}}, \mathrm{M}_{\mathrm{v}}\right)$ representing the turbulent viscosity and diffusivities for velocity, temperature and concentration, respectively). The governing equations using the approximations and the turbulence closure scheme are given by Shen et. al. (1995).

Lake Ontario is a very deep lake in the order of $150 \mathrm{~m}$ at the deepest point however the domain of analysis within this study was confined to the first $25 \mathrm{~km}$ off-shore where the depth is of the order of $60 \mathrm{~m}$. Therefore, only 12 layers were used. The choice of the number of layers and their thickness was strategically chosen, based on their proximity to the surface. Close to the surface the thickness is smaller to ensure appropriate conditions between the wind and water surface. The vertical 
average current profile is logarithmic with the larger gradient close to the surface and lower gradient close to the bottom (Tsanis et al., 1988) where the water intakes reside in the bottom of the lake few kilometres from shore at depths $12 \mathrm{~m}$ to $21 \mathrm{~m}$. For the study described herein the model was setup on a Cartesian $x-y$ grid at a resolution of $500 \mathrm{~m}$ with open boundaries to the east, west and south. The north was bounded by the shoreline. A 500-metre resolution for the study was required in an effort to capture the extent of plume movement during the 1992 spill, which extended several $\mathrm{km}$ both east and west of the PNGS over the event horizon. The grid size, in terms of resolution, was limited to $500 \mathrm{~m}$ since a smaller grid size of the same domain was found to need very large amount of computer time. The depth was divided into 14 different layers with the layers closest to the surface maintaining the smallest thicknesses as shown in Table 1.

Table 1. Layer depths

\begin{tabular}{ccccccccccccccc}
\hline Layer & 1 & 2 & 3 & 4 & 5 & 6 & 7 & 8 & 9 & 10 & 11 & 12 & 13 & 14 \\
\hline Depth $(\mathrm{m})$ & 0 & 1 & 3 & 5 & 7 & 10 & 12 & 15 & 18 & 21 & 43 & 63 & 103 & 240 \\
\hline Temp $\left({ }^{\circ} \mathrm{C}\right)$ & & & 21.2 & & & & 20.9 & 20.9 & 20.9 & 20.7 & 13.7 & 6.3 & 6.3 & 6.3 \\
\hline
\end{tabular}

A representative lake temperature profile, also shown in Table 1, for the August period was obtained from a field exercise carried out as part of the Toronto/Durham water management study during 1999. Shoreline geometry and water depth information used in the modeling process were compiled from Canadian Hydrographic Service charts No. 2000, 2077 and 2058. The Lake is elongated in the northeast direction with a total length of approximately $320 \mathrm{~km}$. The widest section of the Lake is significantly smaller with a length of approximately $85 \mathrm{~km}$. All hydrographic service charts were rotated by 20 degrees clockwise as shown in Figure 2 . This operation minimized the size of the depth grid needed to model $40 \mathrm{~km}$ span between stations and the several $\mathrm{km}$ into the lake from the shore and aligned the longest fetch along the $x$ axis and the shortest fetch along the $y$-axis. Key input parameters for the model include wind drag coefficient, horizontal and vertical eddy diffusivity values for temperature and constituent concentration in addition to horizontal and vertical eddy viscosity values for the momentum equations.

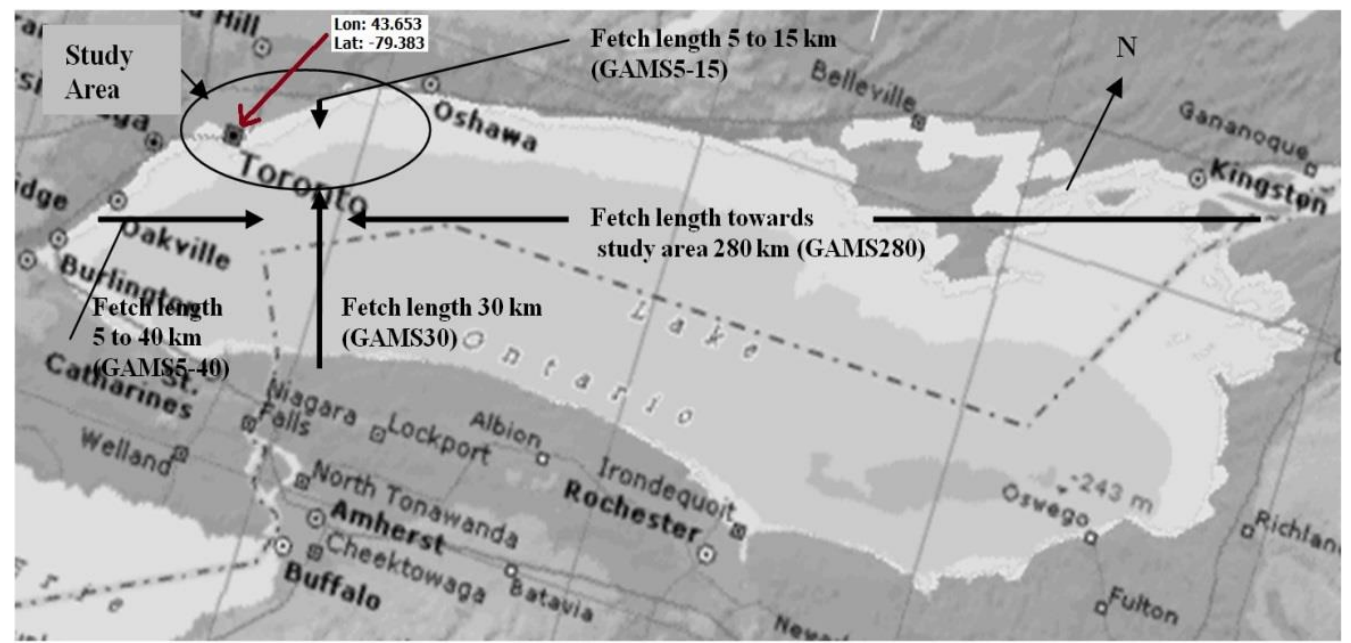

Figure 2. Lake Ontario geometry showing the extent of the study area (east from Toronto, Lon: 43.653 Lat: -79.383)

\section{The Inverse Model}

Inverse modeling was carried out using UCODE, a computer code for universal inverse modeling. The UCODE model is based on posing the differences between simulated and observed values as a least squares objective function which is minimized using a modified Gauss-Newton solution algorithm (Hill, 1998). UCODE works by calculating forward difference sensitivities for each parameter to be estimated. The resulting simulated values are compared to observed values to calculate the sensitivity for the parameter. This sensitivity loop is repeated for each parameter to be investigated. Once the difference between simulated and observed values is calculated for each 
perturbed parameter, minimization of the least squared objective function is performed to determine new optimal parameter estimates (Poeter and Hill, 1998). The 3-D model is rerun with these updated parameter values and the change in objective function is monitored. Parameter estimation is considered converged when the sum-of-squared residuals are less than a user defined fraction over three regression iterations. The solution is iterative since the problem is non-linear. Inverse modeling setup involved identification of the 3-D wind driven transport parameters to be estimated, tolerances for the objective function as well as initial parameter estimates and perturbation values. The primary output from the UCODE iterative process were estimates of the parameters which minimized the objective function in addition to the sensitivity of each parameter at each observation.

\section{FIELD DATA}

The Pickering Nuclear Generating Station (PNGS) is located on the north shore of Lake Ontario, Canada. On August 02, 1992 a total tritium spill quantity of $5.4 \mathrm{E} 14 \mathrm{~Bq}$ (Becquerels) was accidentally released over a duration of 6-hours from the station (In Canada, current tritium levels in drinking water are orders of magnitude less than the $\mathrm{GL}$ of $7,000 \mathrm{~Bq} \mathrm{I}^{-1}$ near nuclear facilities, and similarly well below the European Union's GL of $100 \mathrm{~Bq} \mathrm{I}^{-1}$ (Canadian Nuclear Safety Commission, 2008)). In the aftermath of the spill, tritium data measurements in $\mathrm{Bq} \mathrm{l}-1$ were made at several existing water intakes for the period August 2-27 by Ontario Hydro and the Ontario Ministry of the Environment. The five key locations are shown in Figure 1 and include Ajax and Whitby, approximately 5.0 and $12.5 \mathrm{~km}$ alongshore to the east of the PNGS and Horgen, Harris and Toronto Island, approximately $11.0,21.0 \mathrm{~km}$ and $30 \mathrm{~km}$, respectively, alongshore to the west. Sampling occurred at intervals of between 1 and 2 hours over the 4 week post-spill period at each of the intake cribs which are located at various depths as follows; Ajax $10 \mathrm{~m}$, Whitby $18 \mathrm{~m}$, Harris $12.2 \mathrm{~m}$ and Horgen $19 \mathrm{~m}$ and Toronto $10 \mathrm{~m}$. The wind for the corresponding period of record was obtained from the Toronto Headland wind station situated on the Toronto Outer harbour. This station is located within the study area closest to the existing Toronto Intakes. The records included wind speed and direction for the months of July and August 1992. Calibration of the pollutant transport model to this field data was carried out using two methods; first the traditional trial and error approach and then subsequently using the inverse model.

\section{CALIBRATION TRIAL AND ERROR APPROACH}

The IDOR3D model was setup to simulate the 1992 accidental spill of tritiated water from the PNGS. The pollutant source was simulated as a surface release with a temperature of $21{ }^{\circ} \mathrm{C}$. The total tritium spill quantity of $5.4 \mathrm{E} 14 \mathrm{~Bq}$ was divided evenly over the 6-hour spill duration starting on August 2. The model ran 28 hours prior to the pollutant source release to allow for a warm-up period. Simulation proceeded over 400 hours to ensure full coverage of the actual plume movement between the five existing intake locations modeled in the domain. Several input parameter values which govern the currents and pollutant transport were selected for initial setup with a view that calibration would yield an improved parameter set.

Murthy (1976) who performed dye tests in Lake Ontario found horizontal eddy diffusivities $\left(\mathrm{M}_{\mathrm{h}}\right)$ in the range of 0.01 to $100 \mathrm{~m}^{2} \mathrm{~s}^{-1}$ for length scales corresponding to $100 \mathrm{~m}$ and $15 \mathrm{~km}$, respectively. Studies using drifters in the western part of the lake found horizontal diffusivities of 165 and $22 \mathrm{~m}^{2} \mathrm{~s}^{-i}$ (Pal et al., 1998) for length scales corresponding to 10.1 and $2.1 \mathrm{~km}$ for each of the zonal $(\mathrm{x})$ and meridional (y) directions respectively. A horizontal eddy diffusivity of $10 \mathrm{~m}^{2} \mathrm{~s}^{-1}$ was initially used with a view that calibration would modify this value. According to Martin and McCutcheon, (1999) there are a number of methods available for estimating vertical eddy diffusivity $\left(\mathrm{M}_{\mathrm{v}}\right)$ but, in general, values are in the range of $10^{-3}$ to $10^{-7} \mathrm{~m}^{2} \mathrm{~s}^{-1}$. During calibration a value of $10^{-3} \mathrm{~m}^{2} \mathrm{~s}^{-1}$ was initially selected. Bowie et al. (1985) suggests that horizontal eddy viscosities $\left(v_{h}\right)$ are of the same order as horizontal eddy diffusivities, that is the range is likely between 0.01 to $100 \mathrm{~m}^{2} \mathrm{~s}^{-1}$. To narrow this even further calculation of the horizontal eddy viscosity coefficient was based on the (Tomidokoro, 1984) empirical formula

$v_{\mathrm{h}}=0.001 \Delta_{\mathrm{h}}{ }^{4 / 3}$

where $\Delta_{h}$ is the horizontal grid size. Equation 1 yields a value of approximately $4 \mathrm{~m}^{2} \mathrm{~s}^{-1}$ for the $500 \mathrm{~m}$ grid. 
Officer, (1976) cites that vertical eddy viscosities $\left(v_{\mathrm{v}}\right)$ range between $10^{-6}$ and $10^{-2} \mathrm{~m}^{2} \mathrm{~s}^{-1}$. For the purposes of this study, the neutral vertical eddy viscosity was set at $10^{-2} \mathrm{~m}^{2} \mathrm{~s}^{-1}$ as an initial condition. This neutral value is used within the IDOR3D model for isothermal cases but is adjusted with the local gradient Richardson number for stratified cases. A bottom stress coefficient of $2.5 \times 10^{-3}$ was adopted for Lake Ontario as suggested by Shen et al., (1995) and Hayashida et al., (1999). Estimates of the wind drag coefficient were drawn from a study performed on Lake Ontario by Simons, (1975) who determined an effective wind stress coefficient of $1.85 \times 10^{-3}$ using a numerical model of Lake Ontario and from Shen et al., (1995) who used a value of $1.3 \times 10^{-3}$ for analysis of a three-dimensional model. Simons, (1984), in a study to evaluate topographic wave formation on wind-driven currents, used a wind drag which varied with speed, specifically $1.2 \times 10^{-3}$ for wind speeds less than $10 \mathrm{~m} \mathrm{~s}^{-1}$, linearly increasing to $2.4 \times 10^{-3}$ at speeds of $20 \mathrm{~m} \mathrm{~s}^{-1}$. An initial value of $1.3 \times 10^{-3}$ was selected as the wind data for the simulation period lay primarily below $10 \mathrm{~m} \mathrm{~s}^{-1}$.

For lake flows, the eddy viscosities and diffusivities in the horizontal plane and the vertical direction are usually given to be $10^{2}$ to $10^{-1} \mathrm{~m}^{2} \mathrm{~s}^{-1}$ and $10^{-2}$ to $10^{-6} \mathrm{~m}^{2} \mathrm{~s}^{-1}$, respectively. As a result of the mathematical approach to modeling pollutant transport, specifically advection, the pollutant concentration is susceptible to large numerical diffusion depending on the grid size. For small grid sizes this numerical diffusion is not significant, for larger grid sizes however, this numerical error must be accounted for. To compensate a grid diffusivity factor is applied directly to the pollutant concentration at the source to counteract the effects of numerical diffusion. In order to quantify this factor, a separate analysis, using several test basins of various grid sizes, was performed to determine an approximate relationship between grid diffusivity at the source and grid size. Analysis on one large domain was not computationally feasible since the grid sizes ranged from $4000 \mathrm{~m}$ to $125 \mathrm{~m}$. Consequently a series of overlapping domains with varying grid sizes was utilized. For each grid a simple pollutant source was introduced, diffusion was set as zero and advective transport over the grid was recorded at predetermined distances from the source. Using the form of the relationship defined by Tomidokoro, (1984), the following relationship was derived for the grid diffusivity factor (at the source) as a function of grid size

$$
\mathrm{S}_{\mathrm{h}}=2.5 \times 10^{-4} \Delta_{\mathrm{h}}^{4 / 3} \quad \Delta_{\mathrm{h}}>250 \mathrm{~m}
$$

For a $500 \mathrm{~m}$ grid this initial diffusivity factor was determined from equation 2 to be close to ' 1 '. For the same mesh of $500 \mathrm{~m}$, numerical tests indicated a value of grid diffusivity factor to be closer to 2 . This factor when adopted produced the more optimum results. Although turbulence should not depend on the grid size, because it occurs on a smaller scale than the grid size and its effects are parameterized into the variables of mean flow, results in dependency of the eddy viscosities and diffusivities to the mesh size. For the simulation runs where the grid of $100 \mathrm{~m}$ was used for the smaller extent of the domain, the grid diffusivity had a value of 1 . The IDOR3D model was run using the initial key parameter values as summarized in Table 2.

A sensitivity analysis performed by adjusting each horizontal and vertical eddy viscosity and graphically reviewing the results. Results showed little improvement to the fit between simulated and observed values at each of the existing intakes. Additional sensitivity tests on horizontal diffusivity showed some marginal impacts in magnitude and timing. Further tests on the impacts of adjusting the wind drag coefficient were performed and indicated that simulated results were very sensitive to this coefficient. Similar sensitivity to wind drag coefficient was found by Hayashida et al., (1999) in a numerical study of circulation in the region where the Niagara River discharges into Lake Ontario. Simply through a trial and error approach the effects of wind drag were evaluated and results indicated that an improved fit to the field data could be achieved if the wind drag factors were separated according to fetch length. Key fetch lengths around the study area were determined to be $280 \mathrm{~km}$ for winds coming from the east and between 5 and $40 \mathrm{~km}$ (depending on proximity to shore) for winds coming from the west as shown in Figure 2. Other fetches considered were the winds coming from the shore to the north and winds coming over the longer fetch from the south also shown in Figure 2. Analyzing wind drag in this manner has been studied previously on a number of occasions. Using an offshore platform Smith, (1980), analysed 120 runs with onshore, offshore, unlimited fetch and limited fetch cases to investigate the effects of wind speed and wave height on surface drag coefficients. Smith's (1980) findings showed that the variation of wind drag coefficient with wind speed for varying fetch conditions can range between; $0.4 \times 10^{-3}$ and $1.7 \times 10^{-3}$ for long fetches; $0.7 \times 10^{-3}$ and $1.9 \times 10^{-3}$ for limited fetches and; $0.8 \times 10^{-3}$ and $1.4 \times 10^{-3}$ alongshore. While 
the wind drag coefficient values determined by Smith, (1980) are not directly applicable herein, since they fall into wind speed ranges higher than that found in this study, the findings do indicate that fetch length and shoreline proximity can have significant impacts on wind drag coefficient.

Table 2. Parameter summary

\begin{tabular}{ccccc}
\hline Parameter & $\begin{array}{c}\text { Modeling } \\
\text { Parameter ID }\end{array}$ & $\begin{array}{c}\text { Initial } \\
\text { value }\end{array}$ & $\begin{array}{c}\text { Trial and Error } \\
\text { Calibration }\end{array}$ & Inverse Modeling \\
\hline $\begin{array}{c}\text { horizontal eddy } \\
\text { diffusivity }\left(\mathrm{M}_{\mathrm{h}}\right)\end{array}$ & DCCH & $10 \mathrm{~m}^{2} \mathrm{~s}^{-1}$ & $10 \mathrm{~m}^{2} \mathrm{~s}^{-1}$ & $34.2 \mathrm{~m}^{2} \mathrm{~s}^{-1}$ \\
\hline $\begin{array}{c}\text { vertical eddy } \\
\text { diffusivity }\left(\mathrm{M}_{\mathrm{v}}\right)\end{array}$ & DCCV0 & $10^{-3} \mathrm{~m}^{2} \mathrm{~s}^{-1}$ & $10^{-3} \mathrm{~m}^{2} \mathrm{~s}^{-1}$ & $10^{-3} \mathrm{~m}^{2} \mathrm{~s}^{-1}$ \\
\hline $\begin{array}{c}\text { horizontal eddy } \\
\text { viscosities }\left(\mathrm{v}_{\mathrm{h}}\right)\end{array}$ & DCUH & $4 \mathrm{~m}^{2} \mathrm{~s}^{-1}$ & $4 \mathrm{~m}^{2} \mathrm{~s}^{-1}$ & $4 \mathrm{~m}^{2} \mathrm{~s}^{-1}$ \\
\hline $\begin{array}{c}\text { vertical eddy } \\
\text { viscosities }\left(\mathrm{v}_{\mathrm{v}}\right)\end{array}$ & DCUV0 & $10^{-2} \mathrm{~m}^{2} \mathrm{~s}^{-1}$ & $10^{-2} \mathrm{~m}^{2} \mathrm{~s}^{-1}$ & $10^{-2} \mathrm{~m}^{2} \mathrm{~s}^{-1}$ \\
\hline $\begin{array}{c}\text { bottom stress } \\
\text { coefficient }\end{array}$ & GAMSB & 0.0025 & 0.0025 & 0.0025 \\
\hline $\begin{array}{c}\text { wind stress } \\
\text { coefficient }\end{array}$ & GAMS & $1.3 \times 10^{-3}$ & $\begin{array}{c}\text { GAMS280 }=1.9 \times 10^{-3} \\
\text { GAMS5-40 }=0.1 \times 10^{-3}\end{array}$ & $\begin{array}{c}\text { GAMS280 } \\
\text { GAMS5-40 }=0.1 \times 10^{-3} \\
\text { GAMS30 }=0.5 \times 10^{-3} \\
\text { GAMS5-15 }=0.1 \times 10^{-3}\end{array}$ \\
\hline
\end{tabular}

The trial and error approach to calibration proceeded by adjusting only the fetch related wind drag values for the $280 \mathrm{~km}$ and 5 to $40 \mathrm{~km}$ lengths along with the horizontal eddy diffusivity for contaminant transport. The selected parameter values for the final trial and error outcome are summarized in Table 2. The simulated transport at Ajax indicated an early arrival of the plume ultimately producing a double peak. For the transport to Whitby, simulated results were early and significantly lower than field. For Horgen, the simulated peaks maintained fairly good timing but were significantly higher than observed. For Harris and Toronto Island a reasonably good fit between simulated and observed was produced. Trial and error indicated that wind drag was an important parameter in simulating contaminant transport. Moreover, results indicated that a wind drag coefficient that accounted for fetch length improved the fit. Consequently prior to application of the inverse modeling method an analysis of the wind and general currents produced along each fetch shown in Figure 2, was reviewed through an analysis of field wind and current meter data.

\section{WIND - CURRENT CORRELATIONS}

An independent relationship between wind and currents in the area was sought to provide semiphysical evidence for the use of fetch related wind drag coefficients for the study.

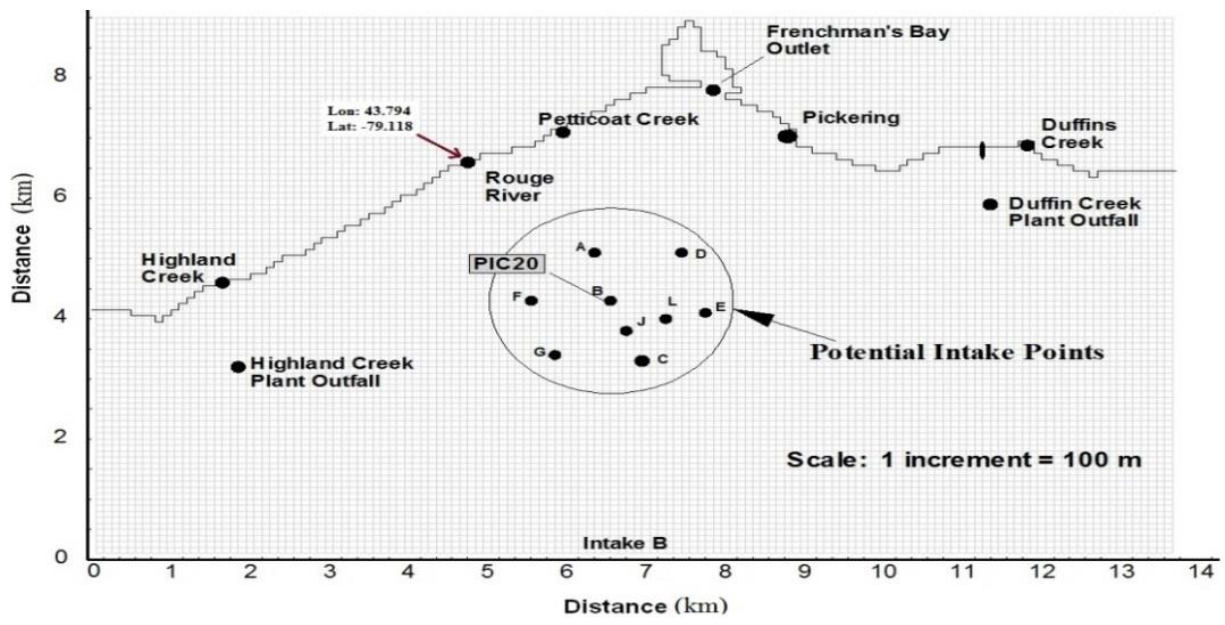

Figure 3. Lake field data collection and potential intake points. The gridded shoreline is in increments of $100 \mathrm{~m}$ and the computational rectangular grid is $100 \mathrm{~m} \times 100 \mathrm{~m}$ 
An extensive program of measurements was undertaken during the period April 1999 to March 2000 as part of the Toronto/Durham water management initiative to collect background data in the assessment of potential drinking water intakes. One of the outcomes of this study was current meter data available within the area of interest as shown in Figure 3 as PIC20.

This data included current meter measurements recorded $5 \mathrm{~m}$ from the top and $5 \mathrm{~m}$ from the bottom at 20 minute time intervals. A period of 6 months of record spanning June to December 1999 from location PIC20 was selected for review.

For the same period of record the hourly average wind speed and direction for each corresponding hour was obtained from the Cherry Beach meteorological station. Both the wind records and the PIC 20 current measurements were subdivided into directions corresponding to the primary fetch lengths analyzed, $280 \mathrm{~km}, 5-15 \mathrm{~km}, 5-40 \mathrm{~km}$ and $30 \mathrm{~km}$. As the current data is susceptible to localized field effects a 6-hr moving average was applied to both the wind and current field measurements. This averaging also assisted in effectively isolating the relationship between wind and currents through persistence. Only wind and current data pairs that were coincident in direction were accepted as valid correlations. Consequently persistent wind and currents that were in opposite directions, as might be the case under the effects of a longshore current, upwelling/downwelling episode or strong historical winds, were excluded from the correlation. The wind and the current speeds were subdivided into $1 \mathrm{~m} \mathrm{~s}^{-1}$ bins and were averaged to represent an estimate of the lake current for each range of wind speed. The average current speed and the corresponding wind speed for each of the primary fetches is shown in Figure 4.

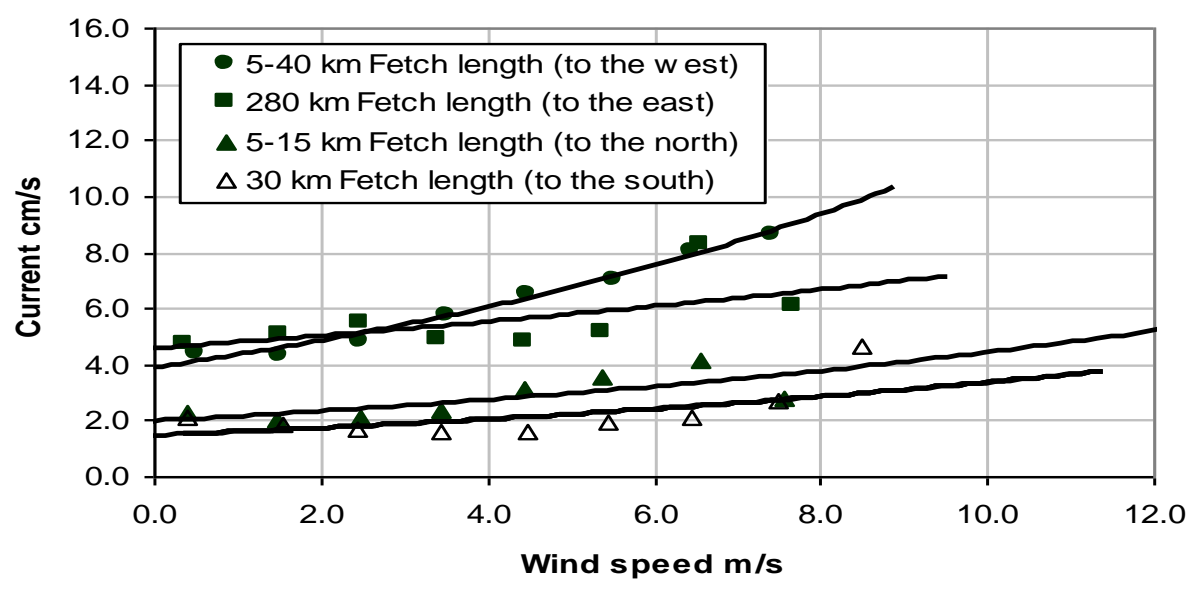

Figure 4. Field wind-current relations at PIC20

Results of this analysis indicate that under various wind speeds, the currents produced from winds moving over the $5-15 \mathrm{~km}$ and $30 \mathrm{~km}$ fetch lengths (cross-shore) are significantly smaller than the 280 and 5-40 km fetch lengths (longshore). Results also show underlying currents are present, approximately $1.0-2.0 \mathrm{~cm} \mathrm{~s}^{-1}$ for the $5-15 \mathrm{~km}$ and $30 \mathrm{~km}$ fetches (cross-shore) and $4.0-5.0 \mathrm{~cm} \mathrm{~s}^{-1}$ for the 280 and $5-40 \mathrm{~km}$ fetches (longshore). The findings are consistent with Rao and Murthy, (2001) who found mean currents of $3-4 \mathrm{~cm} \mathrm{~s}^{-1}$ for an alongshore current at a distance of $3 \mathrm{~km}$ from shore and $1 \mathrm{~cm} \mathrm{~s}^{-1}$ for a cross-shore current at a distance $5 \mathrm{~km}$ from shore. In general, for any given wind speed, results indicate that the effects of wind on current development are different for each fetch length. While there are many shortcomings associated with this type of generalized analysis, such as the use of a uniform wind field and the presence of underlying currents, results do indicate that a single wind drag value applied uniformly across the study area would not correctly capture the impacts of fetch or lake geometry on circulation and ultimately pollutant transport in the study area. On this premise, optimization of multiple wind drag coefficients representing different fetch lengths were analyzed using UCODE.

\section{INVERSE MODELING APPROACH}

While an initial fit was achieved through a trial and error approach, it was clear that additional improvement was necessary and a more quantitative rather than qualitative approach was required to lend support to the parameter values ultimately selected. The primary goals of the inverse 
modeling exercise were to (1) determine statistics that clearly show the sensitivity of each parameter on simulation outcomes, (2) determine parameter values that yield the best possible fit to the observed values, and (3) show the fit of the trial and error approach as compared to the iterative fit provided by the inverse modeling approach.

UCODE works by manipulating the input files of the 3-D wind driven model in order to perturb each parameter to be estimated. Based on the differences between the simulated and observed results for all parameter perturbations, a least squares objective function is formulated and minimized using a modified Gauss-Newton approach. New parameter estimates are inserted into the input files of the three-dimensional model and another iteration of the inverse model performed. The solution is considered converged once the change in the objective function is less than the set tolerance or the maximum number of iterations is reached. For modeling these tolerances were set as 0.01 (UCODE default) and 10, respectively. The maximum number of iterations was set based on Hill, (1998) who suggested that convergence should occur within about two times the number of parameters. For the study herein, the number of parameters to be estimated was 3 (based on sensitivities found in the trial and error approach); hence convergence was expected occur at or around iteration 6.

For each perturbation, the 3-D transport model was run to determine the forward difference sensitivity. Run times for one perturbed value were between three and four hours. Since computation time was an issue, it was important to determine which parameters to include in the regression analysis. GAMS280 and GAMS5-40 are the wind drag coefficients for the $280 \mathrm{~km}$ fetch to the east and the nearshore fetch length to the west around the study area. DCCH is the horizontal diffusivity for contaminant transport. These parameters, particularly the wind drag values, show significant sensitivity and were included in the regression analysis. Wind drag was further analyzed along the opposite fetch representing the $5-15 \mathrm{~km}$ (to the north) and $30 \mathrm{~km}$ (to the south) lengths around the study area as shown in Figure 2. Sensitivity for these parameters indicates that GAMS30 is also significant.

Each parameter perturbation in UCODE involves a forward difference calculation based on a perturbation value defined by the user. One of the concerns associated with this highly nonlinear 3-D problem was the size of the perturbation to be selected. Poeter and Hill, (1998) suggest that the size of the perturbation can be problematic. If too large, the inverse model can yield inaccurate sensitivities for the model parameters. If too small, the results can yield negligible differences between simulated and observed values. As suggested by the UCODE authors experimentation was performed to determine reasonable perturbation values. For the wind drag coefficients and horizontal diffusivity, perturbation fractions found to yield successful convergence were 0.15 and 0.50 respectively. A perturbation value of 0.15 on a wind drag coefficient set at $1.5 \times 10^{-3}$ would therefore perturb the value to $1.7 \times 10^{-3}$. A value of 0.50 for horizontal diffusivity set initially at $10 \mathrm{~m}^{2}$ $\mathrm{s}^{-1}$ would perturb the value to $15 \mathrm{~m}^{2} \mathrm{~s}^{-1}$.

The non-linear inverse problem did not solve successfully when an estimate of all four wind drag fetch related coefficients and horizontal diffusivity was requested. To resolve this, the inverse model was run in two stages. The first started with a view of the three prime parameters which included the wind drag coefficient separated along two fetch lengths $(280 \mathrm{~km}, 5-40 \mathrm{~km})$ and the horizontal diffusivity. The model proceeded through several iterations until convergence was reached. According to Hill, (1998) there are some measures for determining successful inverse modeling. One measure of success is that the modified Gauss-Newton optimization should converge within about twice the number of parameters. For the three parameters estimated in the application herein, the maximum number of iterations was set at 10, convergence occurred at iteration 7 . A graphical review of the simulated versus observed values at each of the existing intakes also showed an improved fit over the trial and error approach indicating a successful inverse modeling run. The optimized parameter values from this first inverse run were applied as a starting condition for a second inverse modeling run, used to estimate the wind drag coefficients for fetches corresponding to GAMS5-15 and GAMS30. The progression of the objective function for these two runs is shown in Figure 5.

The first inverse modeling run was carried out to determine parameter estimates for GAMS280, GAMS5-10 and DCCH starting with the parameter estimates determined from the trial and error approach. As shown in Figure 5 significant improvement in the fit, as indicated by the reduction in objective value, was achieved. A second run for the GAMS5-15 and GAMS30 parameters showed additional but smaller improvement. Optimized parameter values based on inverse modeling are 
summarized along with the trial and error findings in Table 2. A corresponding plot of the results is shown in Figure 6 and are plotted along with observed and trial and error results. Significant improvement was made in simulating contaminant transport to Ajax. The inverse modeling approach reduced the peak at Ajax to match field measured values and eliminated the large double peak experienced during the trial and error approach.

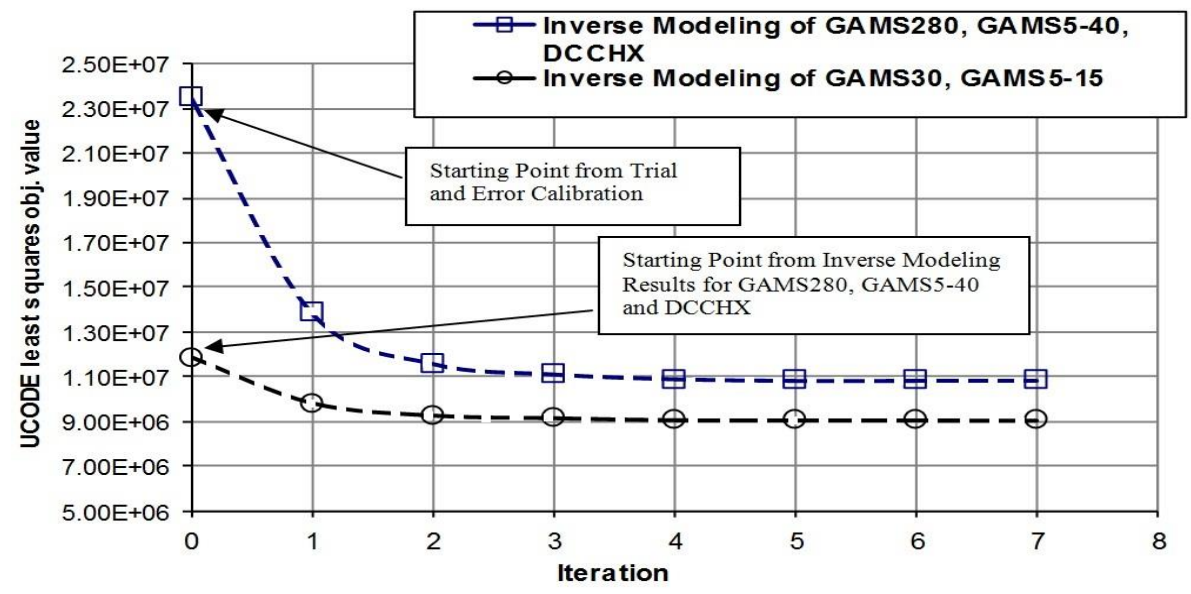

Figure 5. Relation between the Sum of Squared Weighted Residuals and the Parameter Estimation Iteration in the Inverse Modeling Analysis of Model Parameters

Ajax Simulated vs. Observed

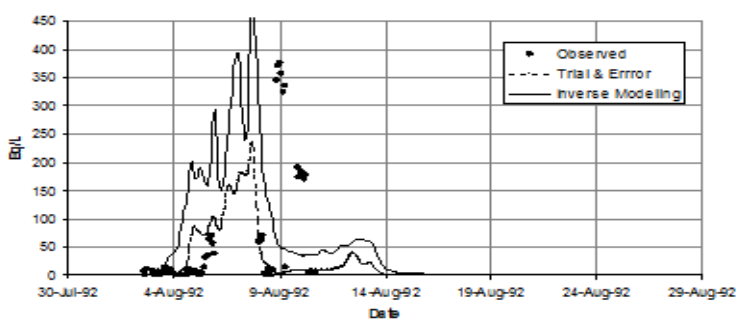

Harris Simulated vs, Observed

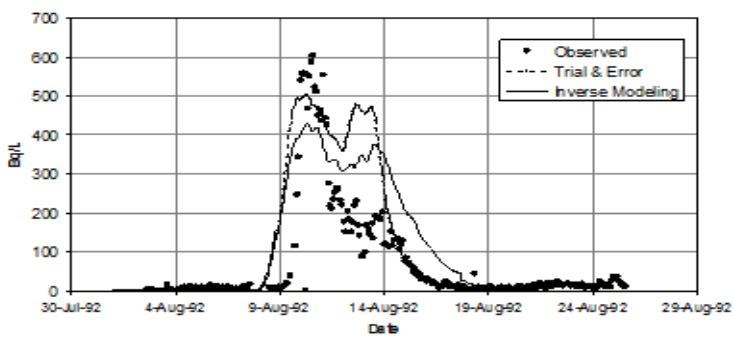

Toronto Simulated vs. Observed

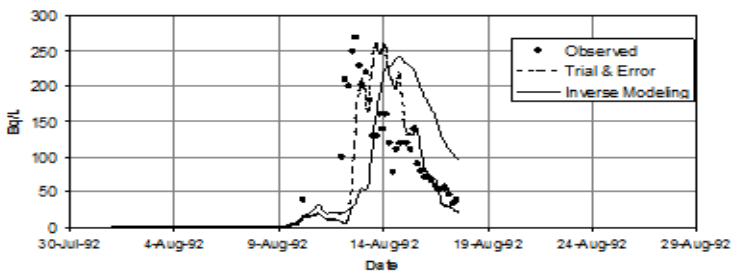

Whitby Simulated vs Observed

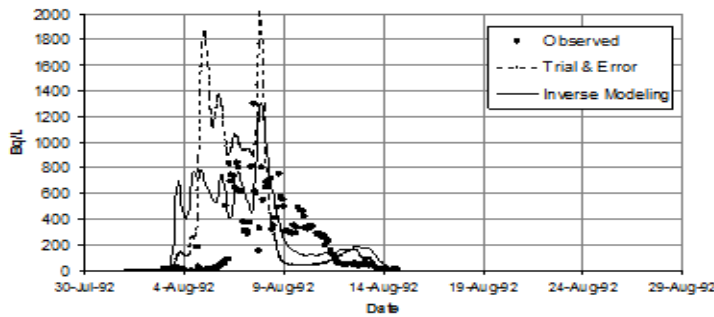

Horgen Simulated vs, Observed

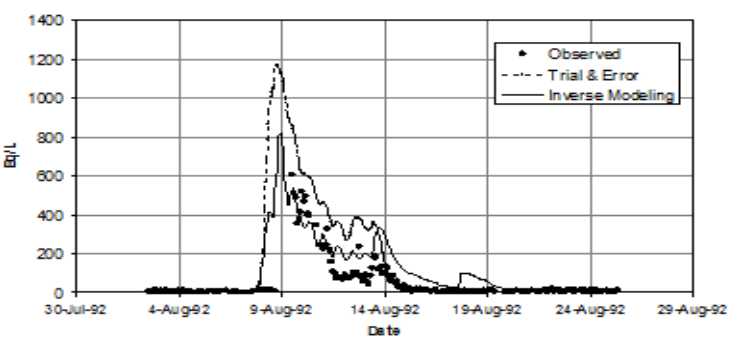

Figure 6: Inverse modeling calibration results

Inverse modeling at Whitby increased the peak to approximate field measurements but did not improve the timing. Results at Horgen were significantly improved while Harris and Toronto showed a slight reduction and offset in timing respectively, with the inverse modeling approach. Inverse modeling yielded wind drag coefficients of $0.1 \times 10^{-3}$ for the short fetch lengths to the west and north (GAMS5-40 and GAMS5-15) close to the shoreline and $0.5 \times 10^{-3}$ for the short $30 \mathrm{~km}$ fetch for winds 
coming from the south. The largest wind drag factor of $1.2 \times 10^{-3}$ was associated the $280 \mathrm{~km}$ fetch. This value is consistent with the general range of values found by Smith, (1980), with the $1.3 \times 10^{-3}$ in Shen et al., (1995) and the $1.2 \times 10^{-3}$ in Simons, (1984).

The small wind drag coefficients are believed to be due primarily to the counter clockwise longshore current which is prevalent within a few kilometres of the shore along (Pal et al., 1998) as well as upwelling and downwelling episodes that also occur within 5-10 km of the shoreline (Rao and Murthy, 2001). For a summer regime Rao and Murthy, (2001) determined the mean alongshore currents on the north shore of Lake Ontario to be toward the west at a mean flow of $3-4 \mathrm{~cm} \mathrm{~s}^{-1}$. This longshore current is not modelled within the hydrodynamic model; consequently wind drag coefficients determined from the calibration exercise will inherently be biased to compensate for this shortfall. In reviewing the transport of the spill plume, it was noted that the field peak at the existing Ajax intake (10 m depth) occurred 125 hours after the spill event implying a current speed of $1.3 \mathrm{~cm}$ $\mathrm{s}^{-1}$ to travel the $5 \mathrm{~km}$ east to Ajax. Winds for the period August $1^{\text {st }}$ to August $6^{\text {th }}$, before and immediately following the spill, were strong winds blowing towards the east at an average $5 \mathrm{~m} \mathrm{~s}^{-1}$.

Under these persistent winds an expected current of $3-5 \mathrm{~cm} \mathrm{~s}^{-1}$ or higher would be more likely, suggesting that the plume should have taken less than 35 hours to reach Ajax. However under the presence of a longshore current moving in the opposite direction from the east, the plume transport would have been impeded significantly increasing the time to travel eastward to Ajax. In modeling this would manifest itself as a reduced wind drag coefficient to compensate as the model is trying to simulate the fact that wind appears to have little effect on plume movement in the presence of a longshore current. Horizontal diffusivity was determined from the inverse model to be $34.2 \mathrm{~m}^{2} \mathrm{~s}^{-1}$. This value is consistent with that of Pal et al., (1998) in which horizontal eddy diffusivities for the western part of Lake Ontario were estimated to be 165 and $22 \mathrm{~m}^{2} \mathrm{~s}^{-1}$ for length scales corresponding to 10.1 and $2.1 \mathrm{~km}$ for each of the zonal $(\mathrm{x})$ and meridional $(\mathrm{y})$ directions, respectively.

\section{RESULTS}

The objective of the study was to calibrate a 3-D wind driven model in order to estimate pollutant levels at several proposed new drinking water intake locations from a possible tritiated water spill. Field data included tritium concentration levels measured over a four week period at several existing drinking water intakes in the aftermath of a tritiated spill from the PNGS. A trial and error approach to parameter estimation yielded a poor fit between observed and simulated data at each of the existing intakes. To quantify the sensitivity of all parameters and to improve the observed versus simulated fit, an inverse model was applied. Results from the inverse model showed a reduction in the sum of squared residuals over the trial and error approach. The scaled sensitivities from the inverse model also indicated that fetch related wind drag coefficients and horizontal diffusivity were key parameters to successful calibration. Inverse modeling results further indicated that, for the study area, the wind drag coefficients representing fetches from the north and west in close proximity to the shoreline should be $0.1 \times 10^{-3}$. This value suggests that other factors such as the longshore current play a larger role in pollutant transport than wind for the summer period. The wind drag coefficient for winds over the $30 \mathrm{~km}$ stretch from the south, were also low at $0.5 \times 10^{-3}$. While this value is in line with findings from Smith (1980), the primary reason for this low value may again be attributed to the underlying longshore current which moves in a counter clockwise direction along the north shore. The result is that the effect of wind on currents is minimized and during calibration a smaller than anticipated wind drag coefficient is produced to compensate. Wind drag coefficient for the $280 \mathrm{~km}$ fetch length was determined to be $1.2 \times 10^{-3}$ from the inverse modeling which was found to be consistent with literature values found in Simons, (1984) and Shen et al., (1995). Horizontal diffusivity was determined from the inverse model to be $34.2 \mathrm{~m}^{2} \mathrm{~s}^{-1}$. This value is also consistent with that of Pal et al., (1998) who found horizontal diffusivities of 165 and $22 \mathrm{~m}^{2} \mathrm{~s}^{-1}$; for length scales corresponding to 10.1 and $2.1 \mathrm{~km}$, respectively.

Using the results of the calibration modeling exercise, the plume movement through the domain was monitored and the levels at each of the potential drinking water intake points designated $A$ through $L$ in Figure 3 were recorded as representative of the tritium levels that would have occurred at the new intakes under conditions similar to the spill of $1992(\mathrm{H}, \mathrm{I}$ and $\mathrm{K}$ were used as reference points, Hurdowar et. al., 2007). The influence of the source inflow 2-3 km into the lake was evaluated to ensure that the study area would be unaffected by its mass and momentum fluxes. The impact of inflow was found to be limited to 3 grids away $(\approx 1.5 \mathrm{~km})$ from the shore. Additionally, the physical 
mixing and handling of flow around a submerged intake was not considered as part of the study. However the space scale difference between the water intake and the grid $(500 \mathrm{~m} \times 500 \mathrm{~m} \times 3 \mathrm{~m})$ is 1-2 orders of magnitude. It was assumed that the tritium concentration within the bottom grid varied minimally within the grid due to the nature of the flow (low currents, turbulence and mostly unidirectional flow) and that concentrations found within the grid were indicative of what may be found at the intake. The results of the proposed intake analysis which indicate that under a spill scenario similar to that of 1992 and stratified lake conditions, all bottom concentrations at the proposed intake locations were below $1000 \mathrm{~Bq} \mathrm{I}^{-1}$. Surface concentrations under the spill conditions were below $8000 \mathrm{~Bq} \mathrm{I}^{-1}$ for locations C-G-J but greater than $7800 \mathrm{~Bq} \mathrm{I}{ }^{-1}$ for locations A-B-D-E-F-L with $D$ and $E$ showing the highest concentrations (Hurdowar et. al., 2007). The calibrated model was used to carry out an assessment of each of the intake locations under the spill of 1992 as well as other wind conditions which would move the plume on a direct path towards the intake envelope.

\section{CONCLUSIONS}

The objective of this study was to determine the concentration levels that would have occurred at potential drinking water intake locations under a spill scenario similar to that which occurred in August 1992 from the PNGS. In the course of the study an inverse model, to estimate parameter values for the three-dimensional wind driven transport model, was used and compared to the trial and error approach. Specifically, inverse modeling with UCODE was used to determine the sensitivity of several input parameters and to determine parameter estimates which minimized the difference between observed and simulated concentration levels.

Inverse modeling proved to be beneficial by providing a clear sensitivity analysis for each parameter and a quantitative approach to parameter estimates. Findings from the inverse modeling also indicated that wind drag coefficient is the most sensitive parameter followed by horizontal eddy diffusivity. In particular it was found that wind drag coefficients defined for each major fetch length would yield a better fit to observed data than a single wind drag value applied over the entire domain. The application of inverse modeling was found to yield and improved fit to field data over the traditional trial and error approach.

\section{REFERENCES}

Bowie G.L., Mills W.B., Porcella D.B., Campbell C.L., Pgenkopf J.R., Rupp G.L., Johnson K.M., Chan P.W.H. and Gherini S.A. (1985), Rates, constants and kinetics formulations in surface water quality modeling, $2^{\text {nd }}$ Edition, Report. EPA/600/3-87/007, U.S. Environmental Protection Agency, Athens, GA. (Cited in Martin and McCutcheon 1999).

Canadian Nuclear Safety Commission (2008), "Standards and Guidelines for Tritium in Drinking Water", p. 12, ISBN 978-0-662-47497-5.

Essaid H., Cozzarelli I., Eganhouse R., Herkelrath W., Bekins B. and Delin G. (2003), Inverse modeling of BTEX dissolutioin and biodegradation at the Bemidji, MN crude-oil spill site, Journal of Contaminant Hydrology, 67, 269-299.

Feddersen F., Guza R. and Elgar S. (2004), Inverse modeling of one-dimensional setup and alongshore current in the nearshore, Journal of Physical Oceanography, 34, 920-933.

Hayashida T., Atkinson J., DePinto J. and Rumer R. (1999), A numerical study of the Niagara River discharge near-shore flow field in Lake Ontario, Journal of Great Lakes Research, 25(4), 897-909.

Hill E. (1998), Methods and guidelines for effective model calibration. A computer code for universal inverse modeling. U.S. Geological Survey, Water-Resources Investigations Report.

Hoffmann J., Galloway D. and Zebker H. (2003), Inverse modeling of interbed storage parameters using land subsidence observations, Antelope Valley, California, Water Resources Research, 39(2), 1-13.

Hurdowar D., Tsanis I. and Simanovskis I. (2007), Application of a three -dimensional wind driven circulation model to assess the locations of new drinking water intakes in Lake Ontario, Journal of Great Lakes Research, 33(1), 232-252.

Martin J.L. and McCutcheon S.C. (1999), Hydrodynamics and transport for water quality modeling, Lewis Publishers.

Murthy C.R. (1976), Horizontal diffusion characteristics in Lake Ontario, Journal of Physical Oceanography, 6, 76-84. (Cited by Martin and McCutcheon 1999) 
Officer C.B. (1976), Physical Oceanography of Estuaries and Associated Coastal Waters, John Wiley and Sons, New York, N.Y. (Cited by Martin and McCutcheon, 1999).

Pal B.K., Murthy R. and Thomson E. (1998), Lagrangian Measurements in Lake Ontario, Journal of Great Lakes Research, 24(3), 681-697.

Poeter E. and Hill M., (1999), UCODE, A Computer Code for Universal Inverse Modeling, Computers \& Geosciences, 25, $457-462$.

Poeter E., and Hill M. (1998), Documentation of UCODE. A Computer Code for Universal Inverse Modeling. U.S. Geological Survey, Water-Resources Investigations Report 98-4080.

Rao Y.R. and Murthy C.R. (2001), Coastal Boundary Layer Characteristics during Summer Stratification in Lake Ontario, Journal of Physical Oceanography, 31, 1088-1104.

Shen H. Tsanis I.K. and D 'Andrea M. (1995), A three dimensional nested hydrodynamic/pollutant transport simulation model for the nearshore areas of Lake Ontario, Journal of Great Lakes Research, 21(2), 161-177.

Simons T.J. (1975), Effective Wind Stress over the Great Lakes Derived from Long-Term Numerical Model Simulations, Atmosphere, 13, 169-179.

Simons T.J. (1984), Topographic Response of Nearshore Currents to Wind: An Empirical Model, Journal of Physical Oceanography, 14, 1393 - 1398.

Smith S.D. (1980), Wind Stress and Heat Flux Over the Ocean in Gale Force Winds, Journal of Physical Oceanography, 10, 709-726.

Tomidokoro G. (1984), Basic Studies on the Hydraulic Characteristics of the Wind Induced Currents and Pollutant Dispersion in Closed Shallow Water Basins. Doctoral Dissertation, Kyoto University, Japan.

Tsanis I.K. and Hurdowar-Castro D. (2005), A Wind Driven Three-Dimensional Pollutant Transport Model, Environmental Modeling \& Software, 20, 1323-1333.

Tsanis I.K. and Leutheusser H.J. (1988), The Structure of Turbulent Shear-Induced Countercurrent Flow, Journal of Fluid Mechanics, 189, 531-552.

Wang C. and Wang P. (2005), Model of Calculating Water Quantity Needed to Dilute and Purify Pollutants in River Network and its Applications, Journal of Hydrodynamics, 17, 418-428.

Wang C., Wang Y. and Wang P. (2006), Water Quality Modeling and Pollution Control for the Eastern Route of South to North Water Transfer Project in China, Journal of Hydrodynamics, 18, 253-261. 